\title{
RPGBIO DROGADIÇÃO: O JOGO ROLE PLAYING GAME (RPG) COMO PRÁTICA NO PROCESSO DE ENSINO E APRENDIZAGEM
}

\author{
RPGBIO DROGADIÇÃO: THE GAME ROLE PLAYING GAME (RPG) AS PRATICE IN \\ THE TEACHING PROCESS
}

\author{
Lurdes Zanchetta da Rosa \\ Instituto Federal Farroupilha/lurdes.zanchetta@iffarroupilha.edu.br \\ Carlos Gabriel Moreira de Almeida \\ Pontifícia Universidade Católica do Rio Grande do Sul/ carlos.gabriel@acad.pucrs.br \\ Filipe Zimmer Dezordi \\ Universidade Federal do Pampa/zimmer.filipe@gmail.com
}

\begin{abstract}
Resumo
Este artigo tem por objetivo apresentar os resultados da elaboração e aplicação do jogo RPGBIO drogadição em instituições de ensino. Esse jogo é parte de um projeto desenvolvido para implementar uma prática educativa, com a finalidade de problematizar e discutir o tema drogadição nas instituições de ensino. Esse jogo tem como modelo as regras do Role Playing Game (RPG), onde cada jogador interpreta um personagem com as características que desejar, podendo interagir livremente com outros personagens, professores e estudantes, contemplando assim, a metodologia dialética. O material do jogo foi elaborado, adaptado e confeccionado por acadêmicos e docentes do curso de Licenciatura em Biologia da UNIPAMPA e do IFFar,RS e, aplicado em quatro turmas de Licenciatura em Biologia e em dez turmas do Ensino Médio, resultando num ambiente de reflexão e questionamento. Além disso, verificou-se uma melhora na aprendizagem desta temática demonstrada pelo interesse e participação nas discussões, após o jogo. 0 referencial teórico e metodológico que embasa a proposta parte de Freire (1992, 1996, 2011) e Sartori (2013). O jogo se configura em uma proposta de ensino que alia conteúdos de Biologia a temas de cunho social, desafiando educadores e educandos a refletirem suas ações, frente às questões inquietantes do mundo.
\end{abstract}

Palavras-chave: jogo, drogadição, prática de ensino

\section{Abstract}

This article aims to present the results of the elaboration and application of the game RPGBIO drogadição in educational institutions. This game is part of a project developed to implement an educational practice, with the purpose of problematizing and discussing the topic of drug addiction in educational institutions. This game is modeled after the Role Playing Game (RPG), where each player plays a character with the characteristics that he wants, being able to interact freely with other characters, teachers and students, thus contemplating the dialectical methodology. The game material was prepared, adapted and made by academics and professors of the Biology Degree course of the UNIPAMPA and 
the IFFar,RS end, applied in four classes of Biology Degree and in ten High school classes, resulted in an environment of reflection and questioning. In addition, there was an improvement in the learning of this theme demonstrated by interest and participation in the discussions after the game. The theoretical and methodological framework that bases the proposal starts from Freire $(1992,1996,2011)$ and Sartori (2013). The game consists of a teaching proposal that combines Biology contents with social themes, challenging educators and students to reflect their actions, in the face of the worrisome questions the world.

Keywords: Play, drug addiction, teaching practice

\section{Introdução}

$\mathrm{Na}$ perspectiva dialógica na qual o homem é um ser essencialmente imaginário, Morin (2005) o caracteriza como faber (trabalho), ludens (jogo) e demens (loucura). Ao interpretar personagens, quer no trabalho ou nas relações sociais, o homem traz 0 imaginário da infância para a fase de adulto. Após a infância, ele precisa saber inventar uma nova redoma em que possa brincar de ser criança num processo de formação, contemplando a multidimensionalidade do ser humano que permanece como um ser inacabado.

Partindo desse pressuposto, elaboramos o jogo RPGBIO drogadição, tendo como objetivo geral abordar, de forma diferenciada, o tema da drogadição na disciplina de Biologia. O jogo é um trabalho interinstitucional entre os cursos de Licenciatura em Biologia e Biotecnologia, da Universidade federal do Pampa (UNIPAMPA),São Gabriel, e a Licenciatura em Ciências Biológicas, do Instituto Federal Farroupilha (IFFar) de Alegrete, ambas localizadas no estado Rio Grande do Sul. Esse jogo consiste numa atividade interativa entre grupos de alunos, mediada pelo Mestre, função desempenhada pelo professor, o qual possibilita um amplo debate sobre o tema, relevante no contexto educacional. Nessa visão, além de provocar reflexões e instigar o diálogo a respeito da drogadição no meio escolar, as estratégias do RPGBIO possibilitam ao estudante complementar e aprofundar o conhecimento dentro dessa temática. $O$ jogo também objetiva estimular o raciocínio globalizante nos estudantes, levando-os a identificar o cenário onde se encontram, com foco no uso abusivo de drogas lícitas e ilícitas e o que pode ser feito para melhorá-lo, num trabalho interativo de diálogo e cooperação.

De acordo com Amaral (2008), "o jogo possui regras que o definem e que orientam o que os personagens podem ou não fazer no transcorrer da partida". Assim, os jogadores dialogam de forma interativa os conhecimentos sobre as drogas e seus efeitos nos órgãos do corpo humano, além de envolver os aspectos socioculturais e familiares dos participantes.

No entendimento de Sartori (2013, p.34), "a ação docente supõe, portanto, estabelecer, na prática da sala da aula, uma atitude dialógica, uma relação respeitosa de fala e de escuta, pela qual professor e aluno discutem os procedimentos considerados 
mais adequados a cada situação de ensino-aprendizagem". Corroborando nesta direção, as palavras de Anastasiou (2012, p.32) afirmam que:

[...] as operações mentais que envolvem jogos interativos, também estão presentes nas ações que operacionalizamos com os estudantes, nos três momentos propostos na metodologia dialética: mobilização, construção e elaboração da síntese do conhecimento, visando ao conhecimento da visão inicial ou sincrética, à efetivação da análise e à busca de uma síntese qualitativamente superior.

Desse modo, o objetivo deste artigo é apresentar os resultados da elaboração e aplicação do jogo RPGBIO drogadição em instituições de ensino.

\section{Os caminhos na construção do jogo}

Para este jogo a fim de facilitar a sua aplicação nas escolas, foi elaborado um conjunto de materiais do RPGBIO, composto por um kit, o qual contém o livro do mestre, com as orientações das regras básicas para a realização da partida. Também fazem parte desse kit os modelos de cartas de personagens, os marcadores de danos de drogas, os marcadores de cura, as cartas de veículos, as cartas de prendas, o tabuleiro representando uma cidade fictícia, os dados multifacetados, a roleta e as figuras em miniaturas. Mapas e fichas do corpo humano, em que são destacados os principais órgãos afetados pelo uso de drogas lícitas e ilícitas, complementam o conjunto desse material. (Figura 1).
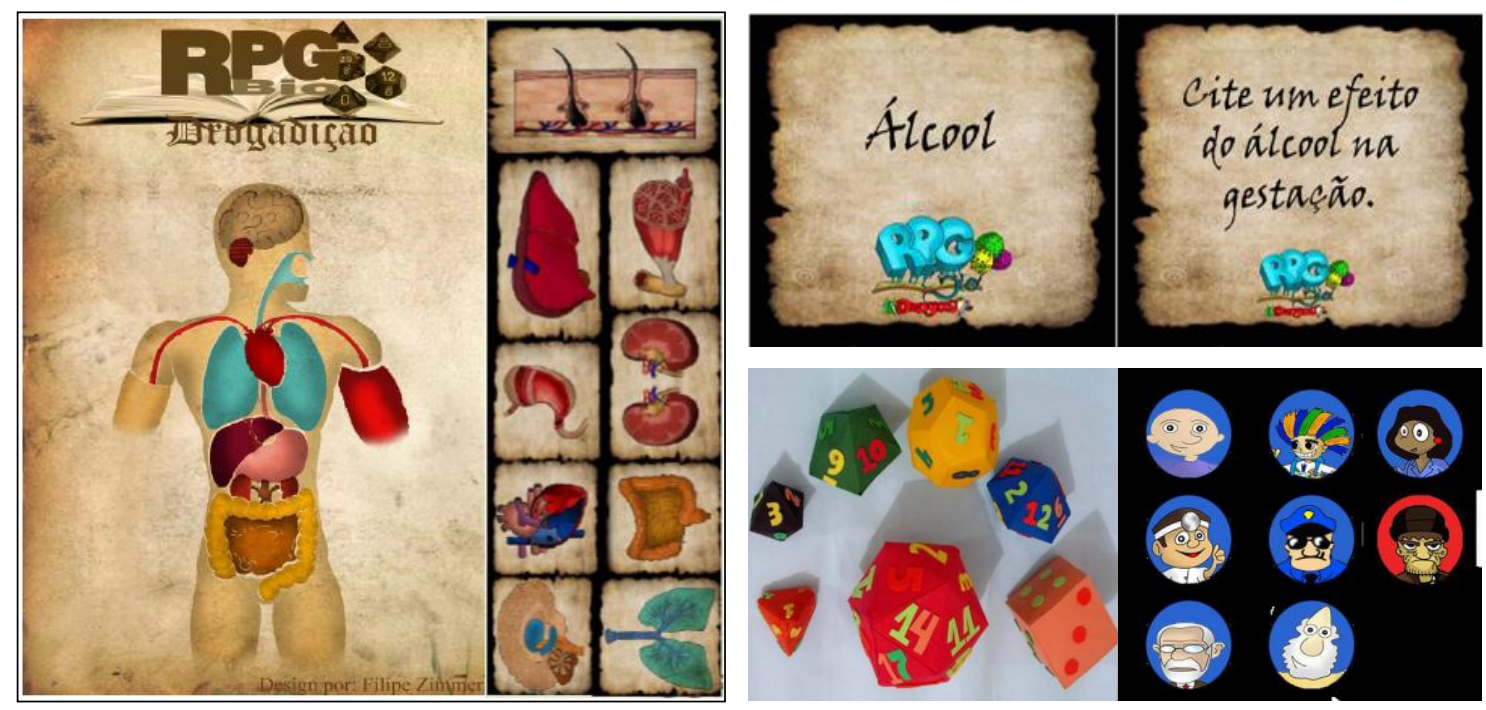

Figura 1. Conjunto de materiais didáticos do jogo RPGBIO Drogadição: mapa do corpo humano, cartas de prendas; dados multifacetados e figuras em miniaturas. 
Para exemplificar, selecionamos algumas cartas (figuras 2 a 7) utilizadas nas partidas do jogo.

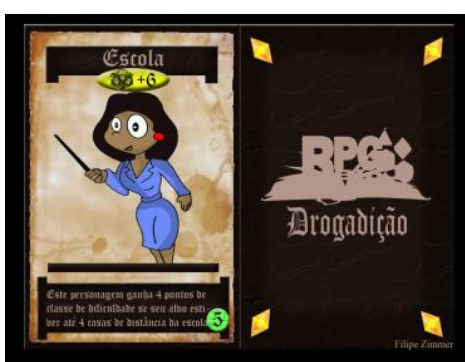

Figura 2. Escola

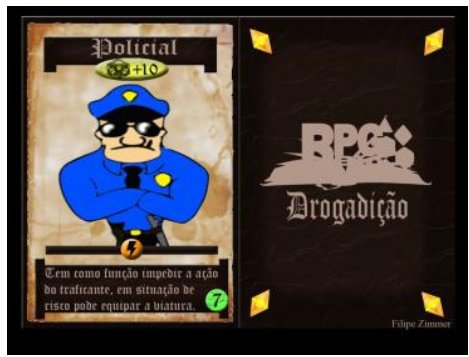

Figura 5. Policial

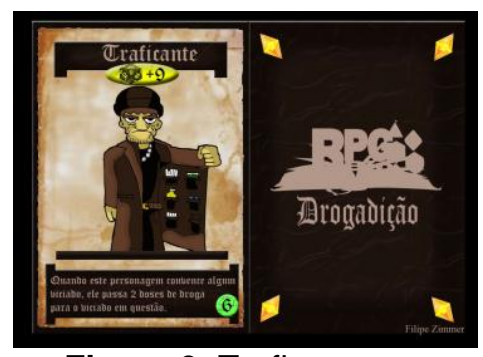

Figura 3. Traficante

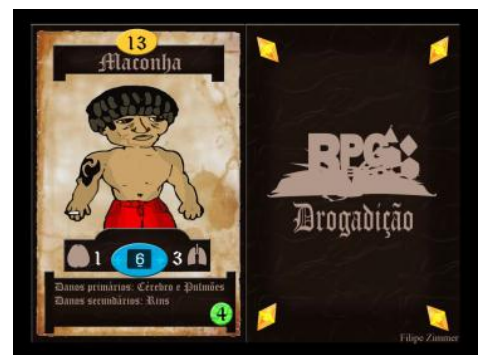

Figura 6. Maconha

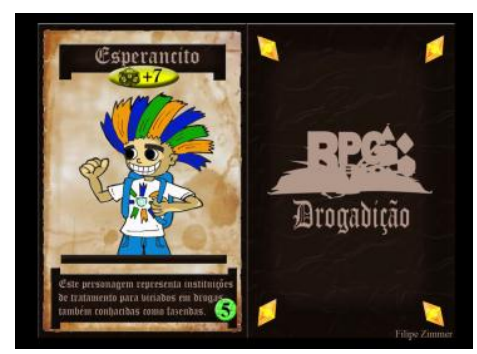

Figura 4.Esperancito

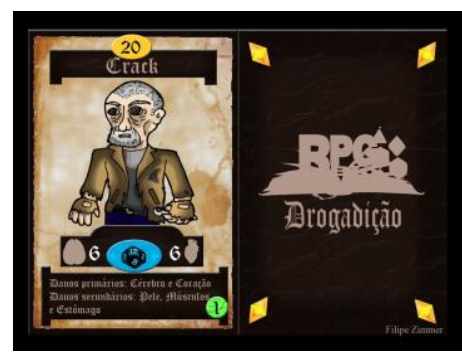

Figura 7. Crack

As cartas do jogo foram inspiradas nos card games (jogos de carta colecionáveis disponível em: https://pt.wikipedia.org/wiki/Jogo_de_cartas_colecionavel). O jogo de cartas colecionáveis (JCC), conhecido pelas siglas em Inglês TCG (Trading Card Games) ou CCG (Collectibles Card Games), consiste numa estratégia, na qual os participantes criam baralhos de jogos personalizados, combinando estrategicamente suas cartas com os seus objetivos. Para esse jogo foram criadas duas versões, uma para ser jogado com os adultos e outra versão para ser jogado com os adolescentes. As regras básicas são as mesmas, porém, o que as diferencia é a interpretação dos personagens de viciados.

As duas versões de cartas, uma para adultos e outra para adolescentes, criadas para o jogo RPGBIO drogadição e aplicadas nas escolas possuem um estilo próprio de ficha de personagem. Antes de iniciar a partida, para cada jogador, é fornecida uma carta que contém as características e as informações de seu personagem, além de incluir a classe de dificuldades como os pontos de movimento e os danos causados aos órgãos(figura 8).

Os personagens foram criados com base em pesquisas de imagens e vídeos da web, para evitar a criação de qualquer tipo de estereótipo. Na criação das figuras de personagens foi utilizando o software Corel Draw X7 e a pintura digital foi realizada através do software Adobe Photoshop CC 2014. 


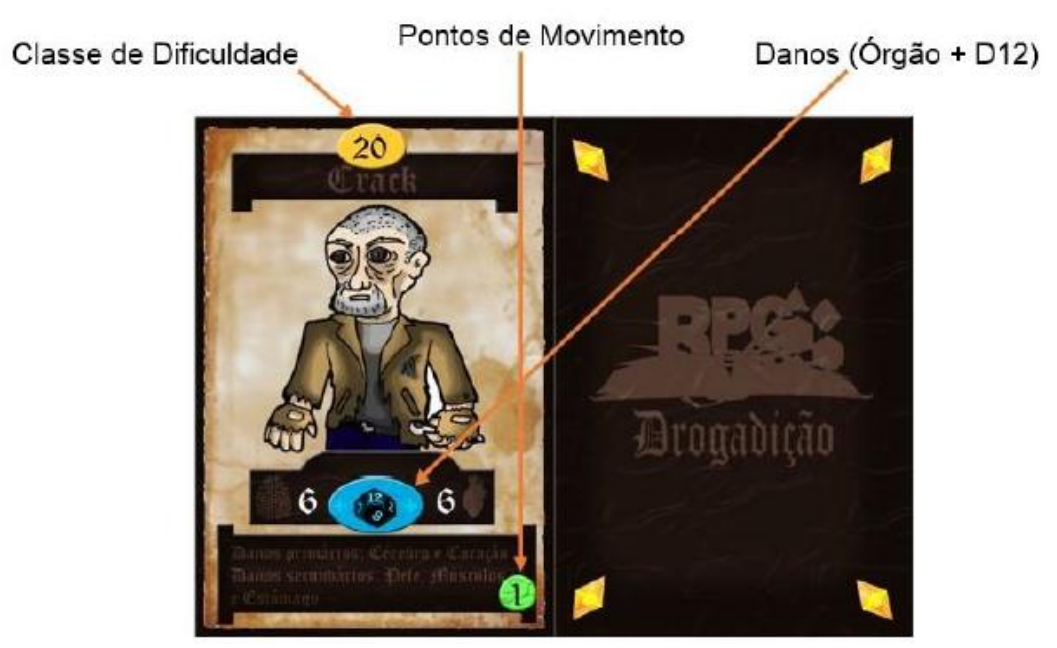

Figura 8. Exemplo de carta de viciado utilizada no jogo com todos os atributos.

A seguir, descreve-se, de forma detalhada, cada atributo da carta de viciado.

- Classe de Dificuldade: A Classe de Dificuldade, ou CD, é o valor mínimo necessário para vencer um desafio ao lançar o dado d20 (vinte faces). Ela é baseada em um sistema de probabilidades, pois tudo tem a chance de dar certo ou errado. Nesse caso, a CD trata do valor necessário para que o jogador consiga convencer o viciado a largar as drogas. Quanto maior for o poder viciante da droga, maior será a CD. Em outros tipos de desafios, cabe ao mestre definir a classe de dificuldade.

- Pontos de movimento: Indicam o número de casas que um personagem pode se mover a cada rodada no tabuleiro, representado pela cidade fictícias (figura 10.b).Drogados geralmente possuem menos mobilidade devido aos efeitos degenerativos das drogas, como por exemplo lentidão de raciocínio e dificuldade de locomoção.

- Danos: existem dois tipos de danos em órgãos: danos primários que são indicados nos cards de NPC's indicado na figura 8, canto direito superior. No exemplo acima, cada vez que o drogado usar crack, o coração e o cérebro perderão seis pontos de vida cada, somados ao valor que o drogado obtiver quando lançar o dado de 12 faces (d12). As cartas especificam os dados a serem lançados para a contabilização de danos em função da toxicidade das drogas. Para uma droga menos tóxica, poderia ser lançado um d6 ou um d8, por exemplo. No que diz respeito aos danos secundários indicados na descrição dos cards e dos NPC's, estes são fixos para todos os cards, sendo seis de dano para cada marcador da droga que estiver sobre a área de marcadores de danos. No exemplo supracitado, a pele, os músculos e o estômago perdem seis pontos de vida para cada marcador de dano de crack. 
As cartas de personagem, chamadas de Card de Personagem, são representadas por um modelo, contendo todas as informações sobre os atributos das cartas dos personagens colecionáveis (JCC) que serão interpretados pelos jogadores. Tais atributos podem ser visualizados na figura 9.

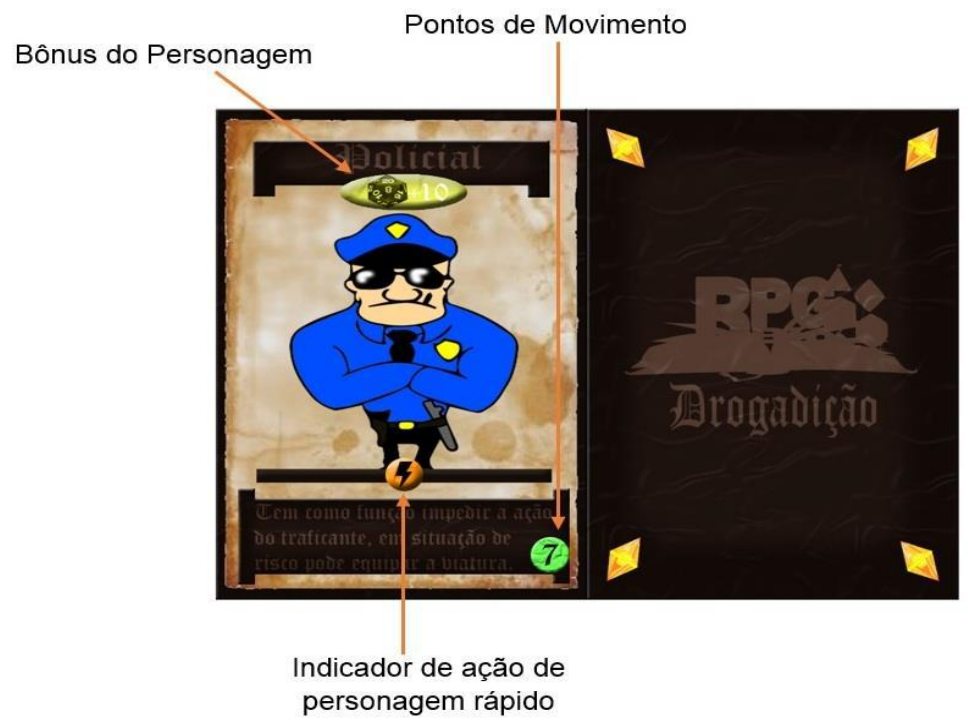

Figura 9. Carta de personagem representando um policial.

A seguir, descreve-se, cada atributo da carta de personagem (não viciado).

- Bônus do personagem: Cada personagem, em um RPGBIO drogadição, possui perícias determinadas por sua classe. Essas perícias conferem pontos de bônus ao personagem. No exemplo acima, toda vez que o policial exercer qualquer ação relacionada à sua profissão receberá dez pontos de bônus que se somarão ao valor obtido no dado d20. Assim sendo, se ele entrar numa perseguição e obtiver oito no dado d20, seu bônus é somado, totalizando dezoito. A finalidade do bônus é aumentar as chances do jogador de obter o valor necessário para vencer o desafio (classe de dificuldade).

- Pontos de Movimento: Indica o número de quadros que cada personagem pode se deslocar no tabuleiro da cidade fictícia, a cada rodada.

- Indicador de ação do personagem: Indica o tipo de ação de cada personagem. Nesse caso, temos um policial que é capaz de intervir imediatamente numa situação de risco e prender o traficante. Por isso é definido como um personagem de ação rápida, diferente da família ou escola que têm por objetivo aconselhar e orientar os adolescentes, de forma menos severa, nos problemas relacionados às drogas.

No trabalho preventivo ao uso de drogas junto à população jovem, a escola e a família ocupam lugar de destaque. Neste sentido, Santos e Bógus (2007) afirmam que, para além do contexto familiar, a escola é o primeiro lugar onde as crianças e os adolescentes estabelecerão novos contatos com o mundo. Também, de acordo com 
esses autores: "cabe ressaltar que os aprendizados desenvolvidos e as relações estabelecidas no ambiente escolar acompanham o aluno no contexto familiar e social". A escola, dessa forma, tem papel fundamental como agente promotor de cidadania e de qualidade de vida dos jovens e adultos.

\section{A construção dos momentos pedagógicos}

Os trabalhos iniciaram com a capacitação da equipe do jogo com o propósito de construir conhecimentos sobre o tema abordado, ou seja, drogadição.

Nessa capacitação a primeira etapa ocorreu pela pesquisa do tema e compilação dos assuntos mais relevantes. Na sequência das etapas, a equipe de trabalho, durante as sessões das partidas do jogo, testou e adequou todo o material do jogo para atender ao seu objetivo, que é abrir espaços de discussão sobre o tema drogadição nas escolas de Educação Básica.

Os procedimentos metodológicos foram organizados em momentos pedagógicos distintos como:

a) Pesquisa prognóstica: feita a partir da aplicação de uma pesquisa qualitativa a partir de questionários semiestruturados de perguntas fechadas e abertas. $E$, também, de debates realizados, por meio de rodas de conversa, com adolescentes e docentes do ensino médio, visando identificar o olhar que os alunos têm em relação às drogas e quais fazem uso ou conhecem. Após análise dos resultados dos entrevistados, foram planejadas as ações pedagógicas junto ao público-alvo.

b) Ações pedagógicas na escola: aulas expositivas dialogadas, apresentando slides acerca das drogas e seus efeitos no sistema nervoso. De acordo com Sanchez et al. (2011), a maioria dos jovens não tem informação adequada e clara sobre os prejuízos decorrentes do uso de drogas, assim, cabe ao educador buscar conscientizá-los sobre tais efeitos negativos.

c) Pesquisas em grupo: busca de referências teóricas pelos alunos sobre "drogas lícitas e ilícitas", na web. Essa metodologia foi adotada seguindo as orientações dos textos de Selbach (2010), da coleção "Como Bem Ensinar", e as contribuições valiosas da obra de "A base da educação é a pesquisa na escola", de DEMO ( 2007).

d) Fase experimental: o jogo RPGBIO drogadição foi aplicado em quatro turmas de Licenciatura em Biologia e em dez turmas do Ensino Médio, bem como no corpo docente das escolas. A dinâmica foi ancorada na metodologia dialética de Vasconcellos (1994). Nesta fase, os participantes foram organizados em grupos de dez componentes, distribuídos ao redor de uma mesa em que estão dispostos todos os elementos como: cartas, tabuleiros, dados e roleta, necessários à partida (Figura 10). A cabeceira é ocupada pelo Mestre, tarefa desempenhada geralmente pelo professor que é auxiliado por um contramestre. Os demais componentes são alunos ou professores participantes na interpretação dos personagens designados ou escolhidos aleatoriamente pelo Mestre. 


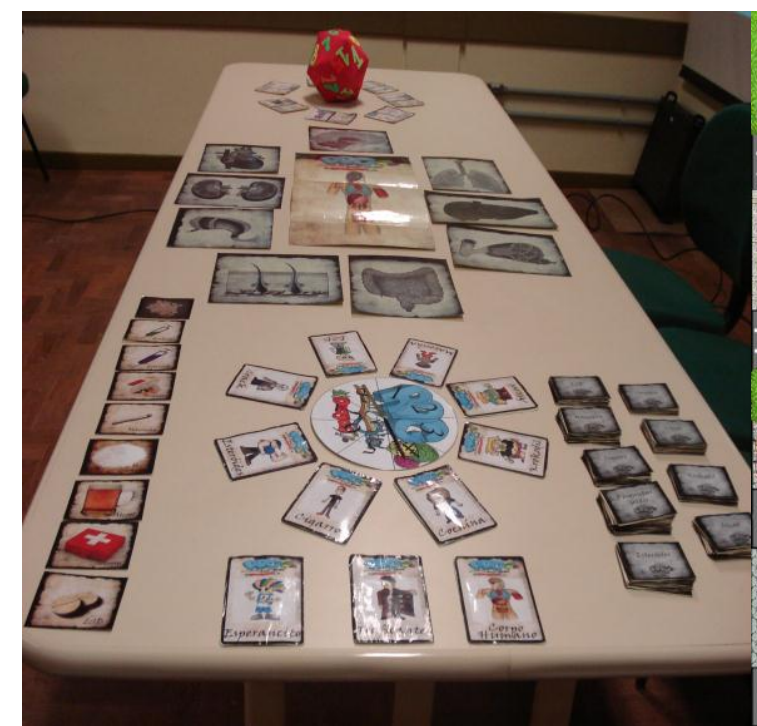

(a)

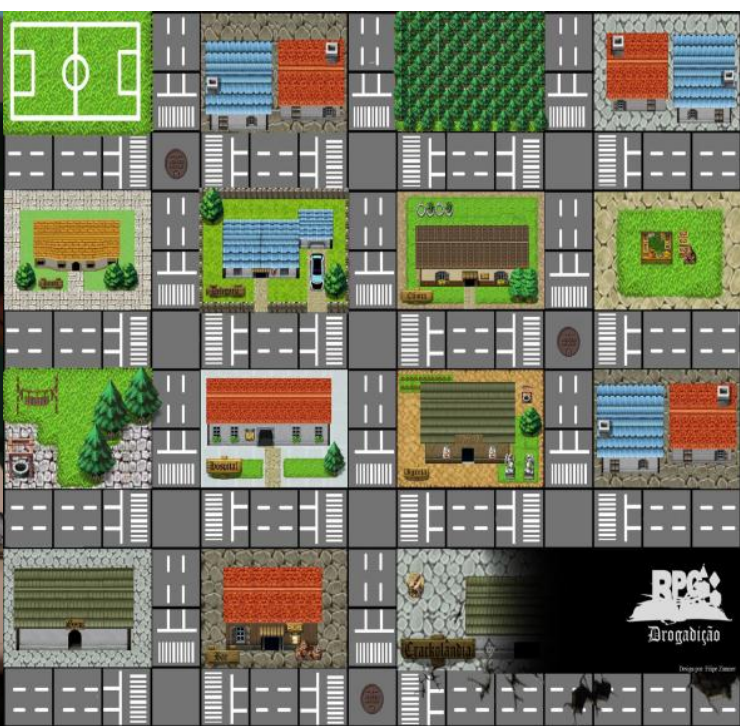

(b)

Figura 10. Mesa do jogo com cartas dos personagens (a) e o Tabuleiro representando uma cidade fictícia, com todos os seus elementos essenciais para as aventuras jogo do RPGbio Drogadição, versões adulto e jovens(b).

As regras do jogo são importantes para orientar e dinamizar a sequência das ações da partida. Na versão adolescente, criou-se uma sequência de ações adaptadas para esta faixa etária, a fim de facilitar as situações de aprendizagem na escola.

O jogo é composto por:

- 07 (sete) Cards de NPC (Non-Playing-Character- em inglês: non-player character, um personagem não jogável/manipulável: Crack, Maconha, Cigarro, Álcool, Cocaína, LSD e Esteroide.

- 08 (oito) Cards de Personagens: Policial, Médico, Psicólogo, Escola, Religião, Esperancito, Cidadão de bem e Traficante (controlado por um adulto responsável)

- 01 (um) mapa do corpo humano.

- 01 (uma) área, para marcadores de danos, composta por nove regiões: rins, pulmões, cérebro, estômago, fígado, coração, intestino, músculo e pele.

- 01 (um) tabuleiro, representando a cidade, composto de oitenta e duas casas para movimentação dos personagens, sendo que três delas são casas de teletransporte (bueiros).

\section{Controles:}

- Os NPC's serão controlados pelo mestre.

- O card de traficante será controlado por um responsável (professor ou ajudante) para não influenciar negativamente nenhum aluno.

- Os personagens são controlados pelos alunos. 


\section{Modo de Jogo:}

- No início da partida, todos os NPC's estão em jogo como usuários de droga, portando uma dose.

- Em cada turno que o NPC's permanece como viciado, o corpo sofre danos indicados pelo card de NPC's.

- A função do traficante é encontrar os NPC's e fornecer-lhes mais drogas. No momento em que o traficante atinge o NPC's, são adicionadas duas doses de droga para o NPC's em questão.

- A função do mestre é gerenciar os turnos dos jogadores, mantê-los motivados e criar desafios para manter o jogo em uma dificuldade equilibrada.

- A função dos personagens é encontrar estes NPC's, remover suas doses e levá-los às clínicas de reabilitação (presentes no mapa da cidade). É atribuição desses personagens também capturar o traficante e conduzi-lo à delegacia.

- A meta no jogo é não deixar nenhum órgão do corpo humano chegar a zero ponto de vida, internar todos os NPC's em clínicas para recuperação e prender o traficante.

- No momento em que um personagem encontrar um viciado, as suas drogas são removidas. A trajetória até a clínica de recuperação dependerá da superação da classe de dificuldade do viciado. Esses pontos são identificados nos cards.

- O NPC pode ser "escoltado" pelo jogador até chegar à clínica, assim, seu marcador fica ligado ao do jogador. O traficante pode interceptar esta trajetória se encontrar o jogador antes de sua chegada à clínica. Simulando ser um familiar ou amigo do NPC, o traficante pode libertar o viciado, se passar em um teste de blefe contra o jogador que está ligado ao mesmo. $O$ traficante rola um dado d20 para determinar o quão boa foi sua mentira, e o amigo do viciado também rola um d20 para determinar se este cairá na mentira. Assim como qualquer outro teste ganha quem obtiver o maior valor. Todo jogador, no topo da carta tem um bônus de personagem que é adicionado ao valor obtido no dado d20 em cada teste realizado.

- O desafio do jogador será o de levar o NPC até a clínica de reabilitação, para ser tratado. Dessa forma, o jogador fica com a carta do viciado que foi reabilitado. Para cada reabilitação o jogador ganha um ponto de bônus, em todos os desafios, ao lançar o dado d20.

\section{Situações de risco:}

Existem dois tipos de situações de risco:

- Quando os pontos de vida de um órgão se aproximarem de quarenta, os personagens podem fazer chamadas telefônicas para a polícia ou para o médico, iniciando imediatamente a vez desses jogadores. Essa ação pode ser realizada quando um personagem estiver no máximo a cinco casas de distância de um viciado, sem poder alcançá-lo ou estiver disputando com o traficante o socorro de um viciado. Nessas situações, o policial e o médico têm seus veículos equipados. 
- Quando o número de viciados for igual ou inferior a três, o traficante tem seu veículo equipado. Também pode ter seu veículo equipado se um dos personagens estiver tentando levá-lo à delegacia, antes dos NPC's estarem internados em clínicas.

\section{Rodadas:}

- Durante uma rodada, cada jogador terá um turno para movimentar-se pelo tabuleiro de acordo com seus pontos de movimentos, visando aproximar-se dos NPC's ou do traficante (exceto médico e policial em situações de risco, podendo ter mais de um turno por rodada).

- No final de cada rodada, deve ser feita a contagem dos pontos de vida de cada órgão. Para auxiliar esta contagem, marcadores de cada droga estarão dispostos nos órgãos e se um órgão estiver com marcador de cura (lado verde do marcador de droga), recuperará dez pontos de vida.

- Após a contagem dos danos, tem início uma nova rodada.

\section{A partida termina se:}

- Todos os viciados estiverem internados em clínicas ou recuperados pelas entidades responsáveis e o traficante preso na delegacia, indicando a vitória dos personagens.

- Algum órgão ficar com zero ponto de vida, indicando a derrota dos personagens.

Se o traficante for preso, os NPC's não estiverem internados em clínicas e não tiverem doses suficientes para levar um órgão a zero ponto de vida, a partida se encerra com vitória dos jogadores.

Outra situação dos personagens é o "pagamento de prendas". Cada vez que um personagem falhar em um desafio (não obtém valor suficiente no dado) deverá "pagar uma prenda" que consiste em responder a uma pergunta sobre o tema drogadição. Quando a turma for numerosa, é aconselhável que cada jogador tenha auxílio de um ou mais colegas. Dessa forma, todos participam ativamente do jogo.

$\mathrm{Na}$ versão para adultos seguem-se as mesmas regras da versão para adolescentes, tendo como diferença a opção dos cards de NPC's poderem ser controlados por outros adultos, ao invés de apenas pelos membros do grupo RPGBIO drogadição.

Assim, as discussões acabam quando o Mestre decidir o momento oportuno para encerrar o jogo após os participantes vencerem, ou não, os desafios propostos ao longo da partida. Esses desafios se dão pela flexibilidade do conhecimento produzido em rede a partir das discussões, pesquisas e rumos que o jogo pode seguir.

A motivação desta proposta metodológica também está ancorada em Freire (1992), quando diz que "a escola, em todos os níveis, precisa abrir espaço para relações que 
priorizem a discussão e o diálogo entre professores e alunos". Dessa forma, complementa Freire (1992, p.43), é pelo diálogo que os homens se aproximam, visto que "o diálogo é o encontro amoroso dos homens que, mediatizados pelo mundo, o "pronunciam", isto é, o transformam para a humanização de todos".

\section{Apresentação dos resultados e suas análises}

Segundo a Organização Mundial da Saúde, estima-se que quase dois terços das mortes prematuras e um terço da totalidade de doenças em adultos são associados às doenças ou comportamentos que começaram na sua juventude, como o abuso de drogas, principalmente o álcool e tabaco (OMS, 2006).

Ainda de acordo com a OMS, droga é qualquer substância não produzida pelo organismo que tenha propriedade de atuar sobre um ou mais de seus sistemas, produzindo alterações em seu funcionamento, ou seja, altera ou causa uma série de mudanças na forma de sentir, pensar, agir e de se expressar. Muitas delas são encontradas nos mais variados locais e situações como nas festas com amigos, supermercados, nos bares, nas farmácias, entre muitos outros lugares. Vale lembrar, também, que o uso e abuso de drogas lícitas, como o álcool, o tabaco, os anorexígenos, os tranqüilizantes, os energéticos, assim como os inalantes, estão carecendo de uma reflexão mais profunda, e mesmo de uma discussão mais ampliada pela sociedade, em vista de seu consumo inadequado em várias idades e de seu poder destrutivo.

Observa-se nas últimas décadas, o aumento do uso indiscriminado de substâncias psicoativas lícitas e ilícitas na sociedade trazendo impacto negativo, como o aumento da criminalidade, marginalização e violência (COUTINHO; ARAÚJO; GONTIÈS, 2004; BARROS, 2004).

Considerando os objetivos do jogo, que são abordar de forma diferenciada o tema da drogadição e também levar os alunos a identificar o cenário onde se encontram e o que pode ser feito para melhorá-lo, com foco no uso abusivo de drogas lícitas e ilícitas, tomou-se o cuidado de chamar a atenção dos estudantes e professores que uma droga por si só não é boa ou má, tendo em vista, que todo o medicamento é uma droga e que deve ser usado, sempre sob prescrição e orientação de profissionais qualificados.

Após a aplicação de uma pesquisa de opinião na escola pública onde o projeto foi desenvolvido, por meio de uma roda de conversa com adolescentes e docentes do ensino médio, identificamos os tipos de drogas mais utilizadas ou conhecidas entre eles. Os dados revelaram que o cigarro, o álcool, a maconha, a cocaína, o crack, os esteroides e o LSD são exemplos de substâncias mais comuns e conhecidas por eles. Nessa perspectiva, prioriza-se especial atenção ao aumento exponencial do consumo de substâncias por parte da população jovem, representando um grave problema mundial de saúde pública (BAUS, KUPEK e PIRES, 2002; CASTANHA; ARAÚJO, 2006). 
Para obter-se um conhecimento mais amplo sobre o tema drogadição os referenciais metodológicos também contaram com uma pesquisa bibliográfica que possibilitou a fundamentação teórica das ideias referentes ao tema em questão. Compõe ainda esse trabalho uma pesquisa documental da avaliação qualitativa registrada em atas, com os depoimentos de alunos e professores em relação a essa metodologia e da necessidade de se trabalhar o tema drogadição na escola. A avaliação foi realizada durante todo o processo do jogo, inclusive a autoavaliação dos componentes do grupo do RPG, a cada etapa de criação (como foi seu desempenho, foi fácil ou difícil, a turma colaborou com você, que sugestões você daria para um próximo trabalho).

A pesquisa qualitativa como referencial metodológico para a pesquisa em Educação tem-se revelado muito valiosa como afirma Minayo (1998), trata-se de um "universo de significados, motivos, aspirações, crenças, valores e atitudes, o que corresponde a um espaço mais profundo das relações dos processos e dos fenômenos que não podem ser reduzidos à operacionalização de variáveis".

Foi realizada avaliação das ações do projeto por meio de questionário semiestruturado e perguntas abertas em 19 estudantes, 29 docentes, quatro estagiários e oito funcionários da escola, para conhecer o "olhar" desta escola em relação ao tema drogadição e para entender a forma de abordagem desse tema, pela instituição.

$\mathrm{Na}$ avaliação qualitativa aplicada após o jogo, verificou-se a aceitação da metodologia do projeto RPGBIO drogadição pelos docentes. Para cada pergunta aplicada foram selecionados alguns depoimentos que constam nos registros em atas das atividades do projeto e exemplificados abaixo:

- Avalie o aprendizado desta manhã:

"[...] Aprendizado maravilhoso, com atitudes que podemos empregar em sala de aula".(aluno $X)$

“[...] Excelente, a linguagem moderna, clara e os assuntos, essenciais".

"[...] Excelente aprendizagem! Contribuiu muito para refletir no nosso ensinoaprendizagem".

"[...] A atividade realizada foi muito construtiva, pois o palestrante expôs sua apresentação tratando da realidade de uma escola, argumentando sobre os comportamentos do professor, do aluno, e como fazer para quebrar estereótipos buscando envolver o professor no contexto de cada aluno para que possam aprender"

"[...] Acredito que a atitude tenha sido muito válida pelo aproveitamento das trocas de experiências e pela abertura que todas as partes envolvidas. O material é muito interessante e importante para se trabalhar na escola".

A partir de algumas respostas obtidas nestas perguntas percebe-se que os docentes são receptivos a novas metodologias e demonstram motivação necessária para melhorar a formação de pessoas livres de preconceitos e respeitosas frente às diversidades. 
- Contribua com sugestões para o desenvolvimento deste projeto. Seu parecer é muito importante:

"[...] Seria muito interessante incluir o assunto na estrutura familiar junto ao trabalho das drogas, como meio de ajudar aos alunos"

"[...] Interagir mais nas escolas, incentivando os alunos na montagem de seus jogos para torná-lo mais abrangente".

"[...] Este trabalho deve ser apresentado nas escolas de Ensino Fundamental onde está começando a formação de caráter das crianças, com sua visão de vida".

"[...] Adorei o trabalho e a forma de sua colocação, apenas trabalharia com um número menor de drogas, ou seja, as mais usuais e de maior giro entre os jovens (público alvo) e, fica assim minha sugestão para que esse projeto seja cada vez mais abrangente, que seja ministrado nas várias esferas sociais, onde há muitos usuários. Acredito que deve ser divulgado em todas as escolas e o material fornecido ou elaborado pela própria escola, que atuará como multiplicadora".

Entre as respostas acima, algumas chamam a atenção pelo fato da necessidade de mais espaços para discussão desse tema, tanto na família quanto nas escolas. A rotina escolar não favorece o diálogo entre seus pares enfraquecendo, ou até mesmo, acentuando os problemas de comportamento e de aprendizagem pelos discentes, nas escolas.

Além do aceite pelo corpo docente da escola, também foi constatado o êxito do método de ensino, por meio da avaliação quantitativa das ações pedagógicas, "antes da metodologia" e "depois da metodologia" de ensino, utilizada em sala de aula em duas turmas pilotos: uma do primeiro ano e uma do terceiro ano do Ensino Médio totalizando dezenove alunos, como pode ser visualizado na tabela 1.

Tabela 1: Médias de notas antes e depois da aplicação do instrumento para alunos do primeiro ano e do terceiro ano do ensino médio em escola estadual no município de São Gabriel, RS. 2014.

\begin{tabular}{|c|c|c|}
\hline \multirow{2}{*}{$\begin{array}{c}\text { Momento de } \\
\text { avaliação }\end{array}$} & \multicolumn{2}{|c|}{ Turma } \\
\cline { 2 - 3 } & Primeiro ano & Terceiro ano \\
\hline Antes & $4,63 \mathrm{a}^{*}$ & $7,75 \mathrm{a}$ \\
\hline Depois & $8,16 \mathrm{~b}$ & $9,44 \mathrm{~b}$ \\
\hline
\end{tabular}

*médias seguidas por mesma letra na coluna não diferem entre si pelo teste $\mathrm{t}$, com $5 \%$ de probabilidade de erro.

$\mathrm{Na}$ avaliação da aprendizagem obteve-se, no primeiro e no terceiro anos do Ensino Médio, significativa melhora nos conhecimentos abordados após a realização do jogo. Estes resultados também podem ser auferidos analisando-se o gráfico (Figura 11). 


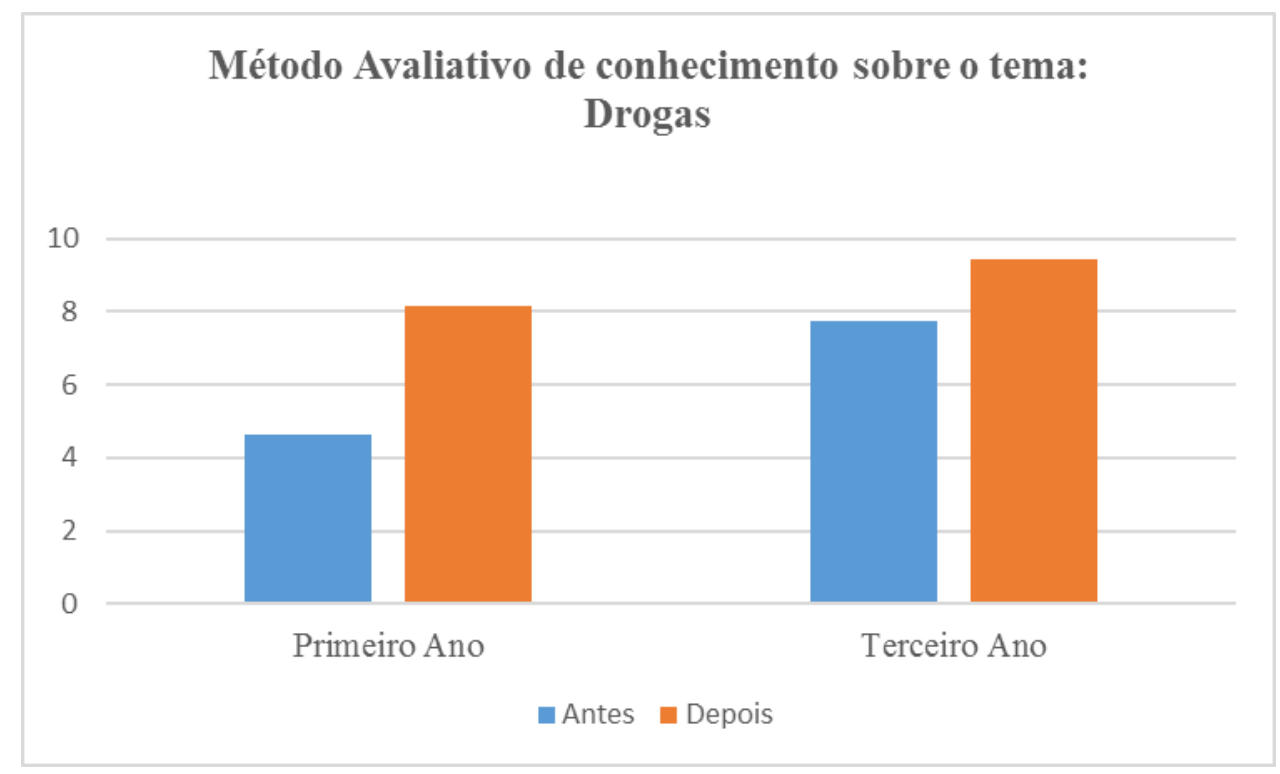

Figura 11: Gráfico do Método Avaliativo de conhecimento sobre o tema: Drogas

Considerando o teste t com $5 \%$ de probabilidade de erro, observa - se que houve diferença significativa entre as notas, antes e depois da aplicação do instrumento, em ambas as turmas trabalhadas. Ainda, pode se observar que a diferença entre as médias foi superior na turma de primeiro ano avaliada.

Através das entrevistas e debates prognósticos percebeu-se, também, que há insegurança e fragilidade do corpo docente na abordagem de assuntos complexos, como por exemplo, as drogas. O que nos faz acreditar que ainda é necessário haver mudanças e comprometimento com uma educação voltada à formação de um cidadão responsável e democrático, preparando-o para conviver de forma harmoniosa e respeitosa, sempre mediada pelo diálogo.

\section{Considerações Finais}

A partir de dados coletados nas avaliações e nas discussões no decorrer das sessões do jogo, percebeu-se que nem sempre o ambiente escolar é aproveitado para apresentar aos alunos situações que os desafiem a uma reflexão sobre questões relacionadas à sua vida. Diante disso é interessante no cotidiano escolar aproveitar situações que permitam o diálogo sobre questões que envolvam as drogas, e buscar saber o que o estudante pensa e sabe sobre o tema, complementando com mais informações, sempre de acordo com o interesse e a capacidade cognitiva de cada faixa etária.

Observou-se, também, pela análise dos depoimentos dos professores, após participarem das atividades do RPGBIO drogadição, a necessidade de mais orientações, capacitações e formações para que os mesmos sintam-se mais preparados e estimulados a trabalhar com o tema, seja por meio de projetos, ou mesmo, durante as aulas. Assim, a proposta do Ministério da Educação, ao procurar orientar a formulação de suas políticas 
educacionais tem seus méritos, porém, precisa de ações voltadas aos professores para que, assim, possa sair do papel e implementar políticas sociopedagógicas efetivamente inovadoras no cotidiano escolar

Levando em consideração a análise do trabalho e do contexto escolar, notou-se que os alunos e professores demonstraram interesse pelo assunto desenvolvido e que uma metodologia diferenciada da "tradicional" chama a atenção.

Dessa forma a avaliação sinaliza que a metodologia foi eficaz e que o tema necessita ser abordado de forma franca a fim de possibilitar o despertar dos alunos que, certamente, passarão a ver sentido no que estão estudando e, que os ajude na tomada de decisões frente aos problemas sérios que acometem toda a sociedade de forma geral que é a drogadição. Ao mesmo tempo, que o diálogo entre os estudantes e professores pode ser uma maneira de fortalecer a autoestima e criar vínculo de respeito, vindo a colaborar para um aprendizado significativo e contribuir de forma decisiva na formação de um cidadão conhecedor dos seus direitos e deveres.

Dentro desta perspectiva, as instituições de ensino envolvidas querem agir diferente, ao menos entender que o despreparo dos jovens pode ser mudado e ser convertido em saberes. É neste contexto que se encaixa o RPGBIO, como uma estratégia de ensino, que valoriza o trabalho em equipe e procura resgatar valores éticos e de convívio harmonioso no âmbito das escolas, e valorizar o que o ser humano tem de mais valioso, que é a vida.

\section{Referências}

AMARAL, Ricardo Ribeiro do. O uso pedagógico do RPG para o ensino de Física. Dissertação (mestrado em Ensino de Ciências) - Universidade Federal Rural do Pernambuco. Recife, 2008. Disponível emhttp://pt.scribd.com/doc/32088015/USO-ORPGPEDAGOGICO-PARA-O-ENSINO-DE-FISICA-Ricardo-Ribeiro-do-Amaral-2008 >Acesso em 02 out. 2014.

ANASTASIOU, Léa das Graças Camargo e ALVES, Leonir Pessate (orgs). Processos de ensinagem na universidade: pressupostos para as estratégias de trabalho em aula.10 ed. Joenvile, SC: UNIVILLE, 2012.

BARROS Dr. Representações Sociais de profissionais das áreas de humanas e da saúde acerca do alcoolismo. (Dissertação de Mestrado em Psicologia Social NãoPublicada). 2004. João Pessoa: Universidade Federal da Paraíba.

BAUS J, Kupek E, Pires M. Prevalência e fatores de risco relacionados ao uso de drogas entre escolares. Revista de Saúde Pública. 2002; 36(1):40-46.

BRASIL. Ministério da Saúde. Informações de saúde. Brasília: Ministério da Saúde, 2009. Disponível em: <http://www.datasus.gov.br>. Acesso em: 26 out.2014. 
Ministério da Educação /MEC. O Jogo do RPG. Disponível em: <http://portaldoprofessor.mec.gov.br/buscaGeral.html?busca=rpg>. Acesso em: 10 set.2014.

. Ministério da Saúde. Secretaria de Vigilância em Saúde. Saúde e prevenção nas escolas: guia para a formação de profissionais de saúde e educação. Brasília: Ministério da Saúde, 2006.

CASTANHA, A.R; Araujo L.F. Álcool e agentes comunitários de saúde: um estudo das representações sociais. Psico USF [online]. 2006; 11(1): 85-94.

COUTINHO, M.P.L; Araújo L.F, Gontiès G. Uso da maconha e suas representações sociais: estudo comparativo entre universitários. Psicologia em Estudo. 2004; 9(3):469-477.

DEMO, Pedro. Educar pela Pesquisa. Campinas: Autores Associados, 2007.

FREIRE, Paulo. Extensão ou comunicação? 10. ed. Rio de Janeiro: Paz e Terra, 1992.

- Pedagogia da autonomia: saberes necessários à prática educativa.São Paulo: Paz e Terra, 1996. - Coleção Leitura.

.Educação e mudança. 34 ed. São Paulo: Paz e Terra, 2011.

MINAYO, M.C. Pesquisa Social: teoria, método e criatividade. Petrópolis:Vozes, 1998.

MORIN, Edgar. O Método 5: A humanidade da humanidade: a identidade humana. Ed. Sulina, Porto alegre, 2005.

SANCHEZ Z.M, OLIVEIRA LG, RIBEIRO LA, NAPPO, SA. O papel da informação como medida preventiva ao uso de drogas entre jovens em situação de risco. Ciências e Saúde Coletiva. 2011; 16(suppl.1):1257-1266.

SANTOS KF, BOGUS, CM. A percepção de educadores sobre a escola promotora de saúde: um estudo de caso. Revista Brasileira de Crescimento e Desenvolvimento Humano. 2007;17(3):123-133.

SARTORI, Jerônimo. Formação do Professor em Serviço. Da (re) construção teórica e da ressignificação da prática. Passo Fundo: Ed. Universidade de Passo Fundo, 2013.

SELBACH, Simone. História e didática. Petrópolis, RJ: Vozes, 2010.

VASCONCELOS, Celso dos Santos. Construção do conhecimento em sala de aula.São Paulo: Libertad, 1994 (Cadernos Pedagógicos do Libertad, no 2).

Submissão: 25/01/2016

Aceite: 01/11/2016 